\title{
Neoformations on stony materials of modern building works
}

\author{
C. Alves*
}

*Centro de Investigação Geológica, Ordenamento e Valorização de Recursos, Universidade do Minho, Campus de Gualtar, 4710-057 Braga, Portugal

Stony materials applied in the built environment interact with diverse pollutants and can originate INORGANIC neoformations that can contribute to depreciation of these materials $[1,2]$.

Microscopy studies help to characterize the chemical and textural features of these neoformations hence contributing to the understanding of the decay processes. In a study of diverse modern constructions in towns of Northern and Central Portugal were identified diverse neoformation substances in stony materials that were sampled and subjected to scanning electron microscopy (SEM) studies. While, in a strict perspective, implying destructive procedures that require the removal of a sample, microscopy techniques require minute amounts and can study occurrences of neoformations that can be detected at the macroscopic level. Products clearly resulting of metals corrosion were not considered in this study.

The dominant inorganic coatings and stains in the studied constructions are carbonate-rich whitish ones that can present diverse morphological features. Some of these carbonate-rich coatings have showed textural features defining a kind of urban travertine and the existence of several layers suggesting diverse episodes of solutions circulation and crystals precipitation, indicating the recurrence of the neoformation processes. Phosphates aggregates were also detected in several built surfaces, including indoor areas (Figure 1a,b). Another relatively common occurrence are efflorescences of more soluble salts, dominated by alkaline sulphates and carbonates (especially sodium sulphate) but were other salts such as alkaline nitrates (Figure 1c,d) and chlorides and magnesium sulphates have also been occasionally found. In some buildings it was possible to observe black crusts resulting from the fixation of atmospheric particles by gypsum aggregates. A very rare neoformation are silica-rich stains that in the situation presented in Figure 1e,f occur associate with calcium carbonate stains and metal corrosion products. The observed neoformations show a great geochemical and textural diversity in the surfaces of stony materials of modern built works, being evidences of diverse possible pollution sources that can interact under variable environmental conditions. Besides an important role that seems to be attributable to mortars materials (namely in relation to calcium carbonates and alkaline sulphates but that might also be the case for the phosphates in inside portions), there are also possible contributions from atmospheric pollutions (in the case of the black crusts) and the presence of alkaline nitrates could be indicative of organic sources as this connection is well established in older works [1]. It has been admitted that alkaline nitrates in these modern works could either represent the persistence of contamination conditions from the past in the soils or the recurrence of the same polluting conditions [3]. Also of particular interest are the textural informations indicating recurrence of neoformation episodes (relevant for possible cleaning interventions) and the chemical associations observed even in some very small samples.

\section{References}

1. Arnold A. et al., The Conservation of wall paintings, Getty Conservation Institute, 103-135, 1991.

2. Sanjurjo-Sánchez J. et al., Environmental Chemistry for a Sustainable World, Volume 2: Remediation of Air and Water Pollution, 47-121, 2012.

3. Alves C., 3rd Internat Conf Integrit, Reliability Failure, Paper Ref: S0108_P0474, 2009. 


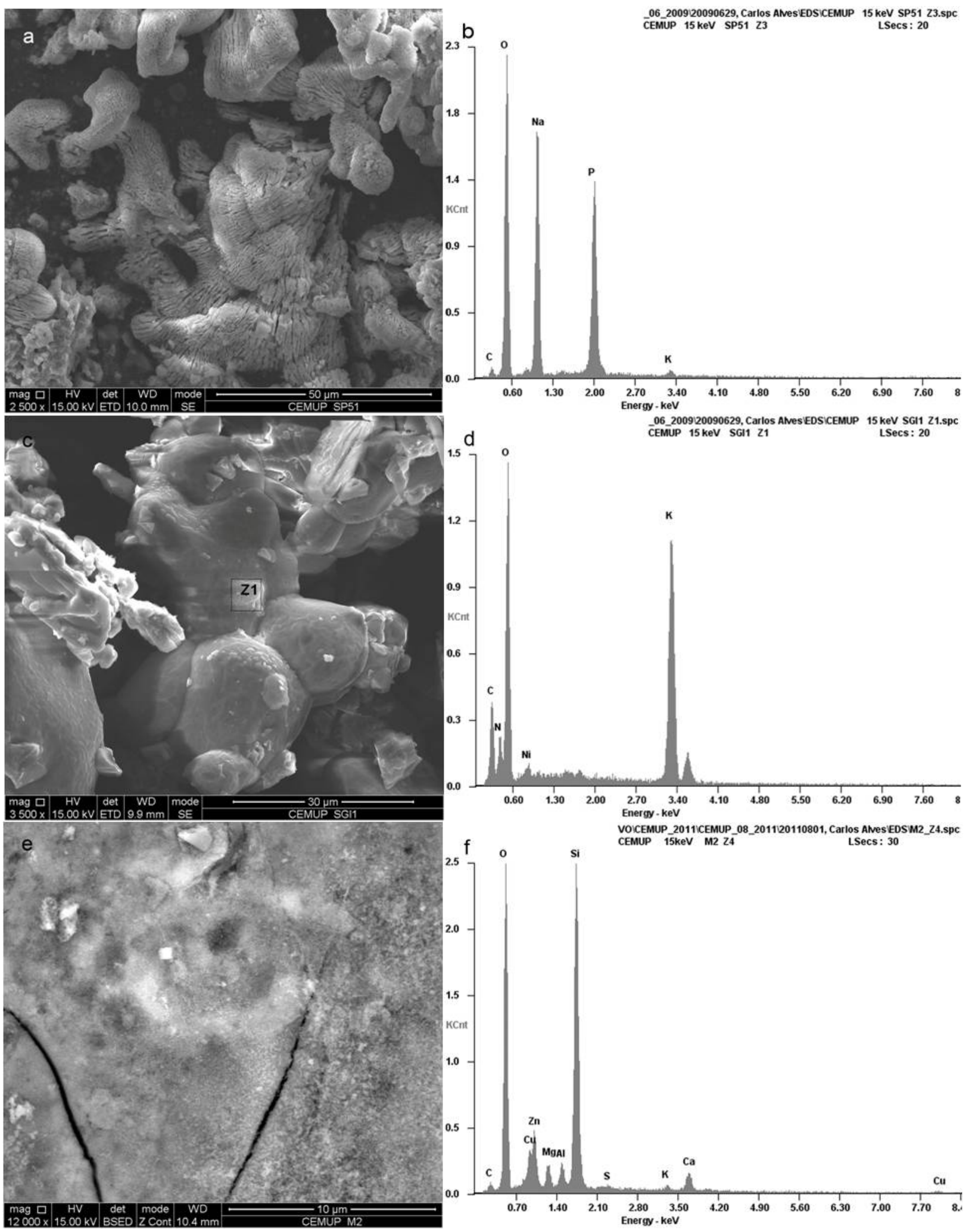

Fig. 1 - Neoformations in modern built works: a), b) phosphate aggregates; c),d) potassium nitrate; e),f) silicarich stains. Analyses performed at CEMUP laboratory (University of Oporto, Portugal).

The author acknowledges the support of the Fundação para a Ciência e Tecnologia (PESTOE/CTE/UI0697/2011, funding by the national budget of the Portuguese Republic). 